\title{
Brain Activation Associated with Automatic Processing of Alcohol-Related Cues in Young Heavy Drinkers and Its Modulation by Alcohol Administration
}

Citation for published version (APA):

Kreusch, F., Goffaux, V., Siep, N., Houben, K., Quertemont, E., \& Wiers, R. W. (2015). Brain Activation Associated with Automatic Processing of Alcohol-Related Cues in Young Heavy Drinkers and Its Modulation by Alcohol Administration. Alcoholism-Clinical and Experimental Research, 39(10), 1957-66. https://doi.org/10.1111/acer.12835

Document status and date:

Published: 01/10/2015

DOI:

10.1111/acer.12835

Document Version:

Publisher's PDF, also known as Version of record

Document license:

Taverne

Please check the document version of this publication:

- A submitted manuscript is the version of the article upon submission and before peer-review. There can be important differences between the submitted version and the official published version of record.

People interested in the research are advised to contact the author for the final version of the publication, or visit the DOI to the publisher's website.

- The final author version and the galley proof are versions of the publication after peer review.

- The final published version features the final layout of the paper including the volume, issue and page numbers.

Link to publication

\footnotetext{
General rights rights.

- You may freely distribute the URL identifying the publication in the public portal. please follow below link for the End User Agreement:

www.umlib.nl/taverne-license

Take down policy

If you believe that this document breaches copyright please contact us at:

repository@maastrichtuniversity.nl

providing details and we will investigate your claim.
}

Copyright and moral rights for the publications made accessible in the public portal are retained by the authors and/or other copyright owners and it is a condition of accessing publications that users recognise and abide by the legal requirements associated with these

- Users may download and print one copy of any publication from the public portal for the purpose of private study or research.

- You may not further distribute the material or use it for any profit-making activity or commercial gain

If the publication is distributed under the terms of Article 25fa of the Dutch Copyright Act, indicated by the "Taverne" license above, 


\title{
Brain Activation Associated with Automatic Processing of Alcohol-Related Cues in Young Heavy Drinkers and Its Modulation by Alcohol Administration
}

\author{
Fanny Kreusch, Valerie Goffaux, Nicolette Siep, Katrijn Houben, Etienne Quertemont, and \\ Reinout W. Wiers
}

\begin{abstract}
Background: While the automatic processing of alcohol-related cues by alcohol abusers is well established in experimental psychopathology approaches, the cerebral regions involved in this phenomenon and the influence of alcohol intake on this process remain unknown. The aim of this functional magnetic resonance imaging (fMRI) study was to investigate the neural mechanisms underlying the processing of task-irrelevant alcohol-related stimuli in young heavy drinkers and their modulation by alcohol administration.

Methods: Twelve heavy drinking male participants were scanned on 2 separate days; once after a low dose of alcohol intake $(0.4 \mathrm{~g} / \mathrm{kg})$, and once after a placebo intake, in balanced order. Images of alcoholic drinks, soft drinks, or neutral objects were shown while participants' neural activity was recorded through fMRI. Moreover, participants' attentional focus was manipulated using a task which required them to process the central images of interest (focus alcohol condition) or a center unattended task (focus not on alcohol condition).

Results: Results indicated that an explicit judgment on beverage-related cues increased activation in the prefrontal area compared with the judgment of neutral objects. By comparison with that of task-irrelevant neutral cues, the processing of task-irrelevant alcohol-related cues increased the activation in a large network of cerebral areas including visual and temporal regions, the bilateral anterior cingulate cortex, the posterior cingulate cortex, and the putamen. Moreover, in the condition with focus not on alcohol, the ventral tegmental area (VTA) was particularly activated by the presentation of (task-irrelevant) alcohol-related cues compared to task-irrelevant soft-drink-related cues.

Conclusions: The VTA was especially involved in the automatic processing of alcohol-related cues in young heavy drinkers. Low dose of alcohol did not modulate the neural substrates involved in the processing of salient alcohol-related cues.
\end{abstract}

Key Words: Attention, Functional Magnetic Resonance Imaging, Alcohol-Related Cues, Heavy Drinkers, Alcohol.

$\mathrm{N}$ UMEROUS MODELS OF addictive disorders state that cues associated with the substance may automatically trigger motivational processes and the addictive behavior (Wiers et al., 2007). According to the incentive salience theory of addiction (Robinson and Berridge, 2003), after repeated associations with drug or alcohol intake, specific environmental cues acquire incentive appetitive properties and therefore powerfully attract attention. Early neuroadap-

From the Faculté de Psychologie (FK, EQ), Université de Liège, Liège, Belgium; Faculty of Psychology (VG, NS, KH), Maastricht University, Maastricht, the Netherlands; Institute of Cognitive Science and Assessment (VG), Luxembourg University, Luxembourg City, Luxembourg; and Faculty of Social and Behavioural Sciences $(R W W)$, University of Amsterdam, Amsterdam, the Netherlands.

Received for publication March 7, 2014; accepted June 29, 2015.

Reprint requests: Etienne Quertemont, Centre de Neuroscience Cognitive et Comportementale, Université de Liège, Boulevard du rectorat 5/B32, 4000 Liège, Belgium; Tel.:+32-4-366-21-05; Fax: +32-4-366-28-59; E-mail:equertemont@ulg.ac.be

Copyright $(0) 2015$ by the Research Society on Alcoholism.

DOI: 10.1111/acer.12835 tations in the mesolimbic structures are suggested to be involved in the attribution of salience to environmental cues (Robinson and Berridge, 2003). These dopaminergic neural circuits, normally activated by natural reinforcements like sex and food, become hypersensitive to alcohol-related stimuli, causing alcohol craving in the presence of such cues.

Brain regions involved in incentive salience have been explored using functional magnetic resonance imaging (fMRI) during a cue-reactivity paradigm. These studies traditionally tried to trigger a state of craving through the presentation of stimuli associated with alcohol. In alcoholdependent patients, the presentation of alcohol-related stimuli elicited activations in the mesocorticolimbic circuit, especially in the orbitofrontal cortex (OFC), the prefrontal cortex (medial and dorsolateral), the amygdala/hippocampal structure, the ventral tegmental area (VTA), the dorsal and ventral striatum (including the nucleus accumbens), the insula, and the anterior cingulate cortex (ACC) compared to neutral stimuli (e.g., Braus et al., 2001; Myrick et al., 2004; Tapert et al., 2004; Wrase et al., 2002; for a review, see Schacht et al., 2013). Among these regions, the OFC and the 
ACC have been, respectively, associated with the evaluation and the encoding of the motivational value of environmental stimuli, while the amygdala/hippocampus complex and the striatum would be involved in the processing of emotional salience of stimuli and the formation of conditioned responses, respectively (Goldstein and Volkow, 2002; Heinz et al., 2009). Data collected among nondependent heavy drinkers revealed the same mesocorticolimbic activation when exposed to alcohol-related cues compared to neutral cues (e.g., Bragulat et al., 2008; Dager et al., 2013; Filbey et al., 2008; Ihssen et al., 2011). Of note, most of these studies used explicit instructions to attend to alcohol-related cues. However, one important manifestation of chronic alcohol consumption is an automatically triggered attentional bias toward alcohol-related cues at the expense of other goalrelated information (for reviews, see Field and Cox, 2008; Franken, 2003). In this study, we thus investigated the neural correlates of this attentional bias for alcohol-related stimuli.

Attentional biases toward alcohol-related cues have been widely studied using various paradigms in alcohol-dependent patients (Johnsen et al., 1994; Noël et al., 2006) and in heavy drinkers (Cox et al., 1999; Townshend and Duka, 2001). Recently, models of addictive behaviors focused on the role of automatically triggered cognitive processes in the development of such behaviors (Stacy and Wiers, 2010; Wiers et al., 2007). According to these theories, alcohol-related cues can automatically trigger a variety of cognitive motivational processes, which in turn can trigger conscious craving and thereby facilitate compulsive consumption of alcohol (cf., Franken, 2003). Consistently, a linear relationship between alcohol consumption and attentional bias toward alcohol-related cues has been found in young habitual drinkers (Cox et al., 2003). Recent findings also indicate that the level of automatic cue reactivity for alcohol-related stimuli can predict relapse in treated alcohol-dependent patients (Garland et al., 2012). However, despite the importance of such automatic processing of alcohol-related cues in problematic alcohol consumption, its neural correlates have hardly been investigated and remain unclear.

Several fMRI studies reported that the amygdala plays a key role in the automatic processing of emotional stimuli, without attention (Vuilleumier et al., 2001) or consciousness (Carlsson et al., 2004). However, conflicting evidence has also been published. For example, emotional stimuli were shown to deactivate the amygdala when presented during a sufficiently demanding concurrent task (Pessoa et al., 2002). This indicates that the amygdala requires some attentional resources to process emotional stimuli (see also Van Dillen et al., 2009). In addition, Siep and colleagues (2009) reported activations in the amygdala and the OFC only during the explicit evaluation of food reward stimuli, but not during automatic processing of food. Regarding alcohol-related cues, only a few recent fMRI studies focused on neural correlates of their automatic processing in alcohol-dependent patients. Vollstädt-Klein and colleagues (2012) used a visual dot probe paradigm in which participants had to detect as quickly as possible a dot probe appearing on either side of the screen and that followed the 50-ms presentation of a pair of pictures, a neutral one and an alcohol-related one. An increased activation in response to alcohol-related cues relative to neutral stimuli was observed within the mesocorticolimbic reward system. A second study compared brain responses to alcohol-related distractors across different levels of alcohol dependence (Fryer et al., 2013). Controls and long-term abstainers, compared with recent and nonabstainers, showed increased recruitment of attention and cognitive control regions when task-irrelevant alcohol cues were presented. Moreover, alcohol abstinence decreased the amygdala recruitment to alcohol-related distractors. Nonetheless, whereas neural correlates of automatic alcohol-cue processing were recently studied in alcohol-dependent patients, cerebral activation underlying this process remains unknown in heavy drinkers.

Regarding the effect of alcohol itself on such processes, some behavioral studies have shown that in heavy social drinkers, the administration of a low dose of alcohol $(0.3$ to $0.4 \mathrm{~g} / \mathrm{kg}$ ) increased both the subjective craving for alcohol (de Wit and Chutuape, 1993) and the attentional capture by alcohol-related cues (Adams et al., 2012; Duka and Townshend, 2004; Schoenmakers et al., 2008; for a review, see Field et al., 2010). However, other studies found that the administration of alcohol modulates the attentional bias toward alcohol only in moderate drinkers (Fernie et al., 2012). More recently, an fMRI study showed that the administration of a low dose of alcohol $(0.4 \mathrm{~g} / \mathrm{kg})$ to moderate drinkers enhanced the processing of alcohol-related but task-irrelevant stimuli. This effect was mediated by the activation within subcortical hypothalamic areas (Nikolaou et al., 2013). In the current study, we therefore tested how a low dose of alcohol $(0.4 \mathrm{~g} / \mathrm{kg})$ would affect the processing of task-irrelevant alcohol-related pictures in heavy drinkers.

In sum, the double purpose of this study was to investigate the neural mechanisms underlying the processing of task-irrelevant alcohol-related stimuli in young heavy drinkers and its modulation by alcohol intake. We scanned 12 heavy drinkers and presented them with a central picture cue that was alcohol related or neutral. To manipulate participants' attentional focus, we asked them to make a judgment on the central picture (i.e., task-relevant cue) or on peripheral bars while the central picture was still presented simultaneously (i.e., now being a task-irrelevant cue; see Pessoa et al., 2005; Siep et al., 2009). We hypothesized that the same mesocorticolimbic pathway found in previous studies on explicit alcohol cue reactivity (Heinz et al., 2009) and during the automatic processing of alcohol-related cues in alcohol-dependent patients (Vollstädt-Klein et al., 2012) should be activated during the automatic processing of task-irrelevant alcohol-related stimuli. Finally, we assessed whether alcohol intake $(0.4 \mathrm{~g} / \mathrm{kg})$ would modulate brain activity during the automatic processing of alcohol-related cues. To do so, participants were submitted to 2 different fMRI sessions, 
following the administration of a mixed alcoholic beverage or of a placebo.

\section{MATERIALS AND METHODS}

\section{Subjects}

Twelve right-handed male students from Maastricht University were paid for their participation (Table 1a). Participants were recruited by advertisement around the University and contacted us by email. They were invited to take part in the study if they reported consuming more than 15 units of alcohol per week on average and experienced at least 1 binge (i.e., 6 or more standard Dutch units of alcohol of $10 \mathrm{~g}$ each on 1 occasion) per week. Upon their arrival for a first scan session, their weekly alcohol consumption was assessed using a self-report daily drinking estimation based on the Timeline Follow Back method (Wiers et al., 1997). They also passed the Alcohol Use Disorders Identification Test (AUDIT; Saunders et al., 1993). The range of AUDIT scores indicated that all participants met the criteria for hazardous drinking (AUDIT score of 8 or above; Babor et al., 2001). None of the participants had any known psychiatric or neurological disorder, as assessed by the participants' self-report on an fMRI screening (Maastricht University) and on the Symptom Checklist-90-Revised questionnaire (Derogatis, 1994). Written consent was obtained from all participants, and the study was approved by the Ethics Committee of the Department of Psychology and Neuroscience, Maastricht University.

\section{Procedure}

The participants underwent 2 fMRI sessions scheduled exactly 1 week apart, 1 after alcohol, and 1 after placebo administration. The 2 sessions took place in the afternoon to maximize the desire for alcohol, and their order was counterbalanced across participants. The participants were instructed not to consume any alcoholic beverage for 24 hours before each fMRI session and not to eat high-fat food the day of the experiment. Alcohol blood concentration was checked at the start of the experiment with a breathalyzer (Lion alcolmeter SD-400; Lion Laboratories Limited, Vale of Glamorgann, UK). In the alcohol session, the participants drank a mix of vodka (i.e., $0.4 \mathrm{~g} / \mathrm{kg}$ body weight of alcohol) and tonic, with a slice of lemon, before entering the scanner. In the placebo session, the participant drank a glass of tonic with sugar to match the calorie content

Table 1. Sample Characteristics and Reaction Times (RTs) at the Task According to the Experimental Condition (Mean and SD)

\begin{tabular}{lrrr}
\hline & $N$ & Mean & SD \\
\hline a. Demographic and consumption data & & & \\
Age & 12 & 21.3 & 2.1 \\
$\quad$ Drink/wk & 12 & 26.4 & 12.1 \\
6 drinks or more in 1 occasion/wk & 12 & 3.2 & 0.9 \\
AUDIT score & 12 & 16.7 & 4.4 \\
b. RTs in the task (ms) & & & \\
Drink attended condition & 7 & 450 & 99 \\
Alcohol session-Alcohol drink & 7 & 473 & 117 \\
Alcohol session-Soft drink & 7 & 462 & 120 \\
Placebo session-Alcohol drink & 7 & 489 & 118 \\
Placebo session-Soft drink & & & \\
Bars attended condition & 7 & 417 & 36 \\
$\quad$ Alcohol session-Alcohol drink & 7 & 438 & 43 \\
Alcohol session-Soft drink & 7 & 443 & 35 \\
$\quad$ Alcohol session-Neutral object & 7 & 427 & 47 \\
Placebo session-Alcohol drink & 7 & 457 & 52 \\
Placebo session-Soft drink & 7 & 470 & 44 \\
$\quad$ Placebo session-Neutral object & & & \\
\hline
\end{tabular}

AUDIT, Alcohol Use Disorders Identification Test. of the alcoholic drink. To keep the smell of alcohol, the top of the glass was dipped in vodka and a slice of lemon soaked in vodka was put on the glass. Moreover, the placebo drink was prepared in front of the participant with tonic in a bottle of vodka (Marlatt and Rohsenow, 1980). After consumption of the drink, subjects filled out a visual analog scale assessing the desire to drink alcohol and the approach and avoidance of alcohol questionnaire (AAAQ; McEvoy et al., 2004). The participants entered the scanner 15 minutes after consumption of the drink and completed the experimental task. Each fMRI session lasted about 75 minutes. At the end of each fMRI session, alcohol blood concentration was again measured.

\section{Experimental Design}

This study used a 3 (picture type: alcoholic drink, soft drink, and neutral object) $\times 2$ (session: alcohol and placebo administration) $\times 2$ (attention focus: object/drink attended and bars attended) within-subject design. Analogous to Siep and colleagues (2009), who studied brain responses to food rewards, participants were shown pictures of alcoholic drinks, soft drinks, and neutral objects in the center of a black background screen (approximately $4^{\circ}$ vertically). These images were collected from www.istockphoto database. Two white bars were placed on either side of the central image at $6^{\circ}$ eccentricity. These bars were either oriented in the same way, or oriented dissimilarly with a difference of $45^{\circ}$ or $90^{\circ}$. Pictures and bars were presented simultaneously in all of the 6 different conditions. Trials of the same condition were presented within blocks of 5 trials. At the beginning of each block, a verbal cue indicated the task to perform (see Fig. 1). In the alcohol attended and soft-drink attended blocks, the cue was "drink?", prompting the participant to judge whether they wanted to drink the presented alcoholic drink or soft drink (yes: index finger, no: middle finger). The neutral objects attended blocks were preceded by the cue "red?", which instructed the participant to indicate whether the presented object was red or not (red: index finger, not red: middle finger). In the 3 bars attended blocks, the cue "bars orientation?" instructed the participant to indicate whether peripheral bars were of similar orientations (same: index finger, different: middle finger). There were 18 blocks of each condition and therefore 90 trials of each condition in total. Fifty percent of the bars matched and 50\% did not. During these bars attended blocks, central stimuli (alcohol, soft drink, or neutral

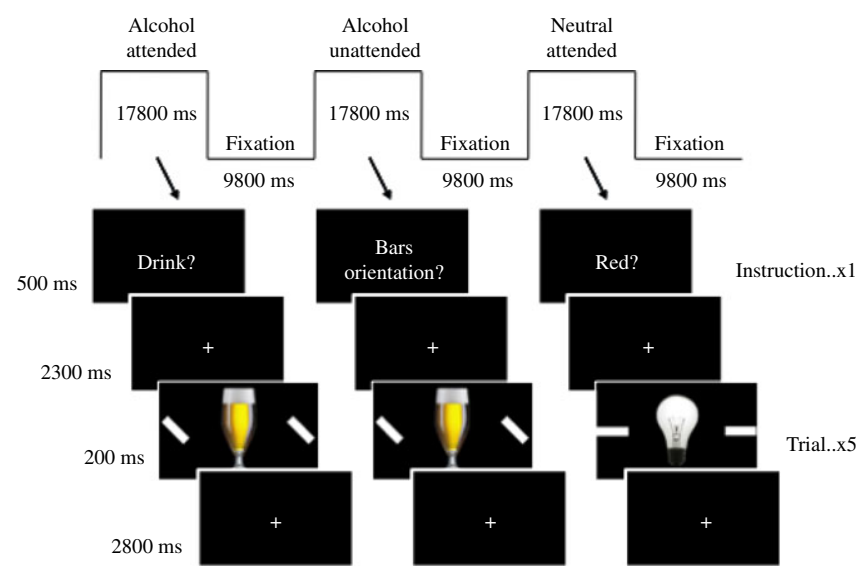

Fig. 1. Graphical outline of the stimulation protocol used in this functional magnetic resonance imaging experiment. Stimuli were presented in a blocked design: alcohol attended blocks, soft-drink attended blocks, neutral attended blocks, bars attended blocks. Throughout the experiment, participants focused on the white fixation cross at center. Stimuli were presented in the center of participants' visual field. At the beginning of each block, a word was presented indicating the task and focus of attention required from participants. 
object) did not require to be attended in order to perform the task correctly. Each picture (alcoholic drink, soft drink, or neutral object) was displayed equally often with matching bars and with nonmatching bars.

\section{Stimulation Protocol}

Each session consisted of three 17-minute runs of experimental blocks and 1 anatomical scan, each separated by a 1-minute break. Each block (18 seconds) consisted of an initial verbal cue (drink?, red?, or bars orientation?; $500 \mathrm{~ms}$ ), followed by 5 display screens consisting of picture stimuli of the same type (alcoholic drinks, soft drinks, or neutral objects) and 2 peripheral white bars for $200 \mathrm{~ms}$ each. These displays were followed by a white fixation cross (2,800 $\mathrm{ms})$, during which the participant had to provide his response. Each block was followed by a fixation cross of 9 seconds. The brief 200-ms display and the positioning of the stimuli within the center of the visual field were aimed at preventing the occurrence of deliberate saccades (Pessoa et al., 2005). Each block type was presented 6 times in a run lasting 17 minutes. The order of the runs was balanced across participants, but was kept constant over sessions within 1 participant.

\section{fMRI Data Acquisition}

Images were acquired with a 3T Siemens Magnetom Allegra Head-only Scanner at the Maastricht Brain Imaging Centre using a birdcage volume coil. Gradient echo-planar imaging volumes were acquired (50 slices, $\mathrm{TR}=3,000 \mathrm{~ms}$, flip angle $=90^{\circ}$ ). Imaging parameters were optimized to minimize susceptibility and distortion artifacts in OFC. The relevant factors included oblique axial imaging with a negative (i.e., backward) tilt angle of $30^{\circ}$, minimizing voxel size $(2 \mathrm{~mm} \times 2 \mathrm{~mm} \times 2.5 \mathrm{~mm})$ in the plane of the imaging, a short echo time of $25 \mathrm{~ms}$, and a high imaging bandwidth $(2,790 \mathrm{~Hz}$ over the field of view, echo spacing $=0.4 \mathrm{~ms})$. The voxel matrix size was $128 \times 104$ and the field of view was $256 \mathrm{~mm} \times 208 \mathrm{~mm}$. Acquisition of functional images yielded 340 volumes per run. One high-resolution whole-brain anatomical T1-weighted scan was also acquired $(\mathrm{TR}=2,250 \mathrm{~ms}, \mathrm{TE}=2.6 \mathrm{~ms}$, flip angle $\left.=9^{\circ}, 1 \mathrm{~mm} \times 1 \mathrm{~mm} \times 1 \mathrm{~mm}\right)$.

\section{fMRI Data Preprocessing}

All processing and analyses of the fMRI data were performed using BrainVoyager QX 1.9 ${ }^{T M}$ (Brain Innovation, Maastricht, the Netherlands). The first 2 volumes of the T2*-weighted functional images were discarded due to magnetic saturation effects. Preprocessing comprised slice scan timing correction (using sinc interpolation), motion correction (using a 3-dimensional rigid-body transformation of each volume to the first volume of each run and using trilinear/sinc interpolation), and high-pass filtering to remove low-frequency noise (up to 3 cycles in the single run time-course). Individual functional data were smoothed using a 6-mm full-widthat-half-maximum isotropic Gaussian Kernel. The anatomical scan and the functional data were then spatially normalized using Talairach transformation procedures. For group analyses, the normalized individual functional data were averaged and standardized with a $\mathrm{z}$ transformation.

\section{Behavioral Data and Statistical Analysis}

Equipment failure resulted in the loss of behavioral data of 5 participants for 1 session. Behavioral analyses were then conducted on 7 individuals. We analyzed reaction times (RTs) with 3 (stimulus: alcoholic drink, soft drink, neutral object) $\times 2$ (session: alcohol or placebo) repeated-measures analyses of variance (ANOVAs), separately in bars attended and object/drink attended condition given the different instructions. Responses in bars attended and object/drink attended were also analyzed with "stimulus" $\times$ "session" repeatedmeasures ANOVAs.

\section{fMRI Statistical Analyses}

Analyses were performed in BrainVoyager. Blood oxygen-level dependent (BOLD) responses were modeled by convolving the hemodynamic response function with a boxcar function representing blocks, from the onset of the instruction screen to the onset of the interblock fixation period. A random-effects (RFX) factorial model was used to analyze BOLD responses, with factors "session" (2 levels: alcohol or placebo), "attention" (2 levels: object/drink attended or bars attended), and "stimulus" (3 levels: alcohol, soft drink, or neutral object).

We computed different analyses. First, brain activations after alcohol administration (alcohol session) were contrasted with those of the placebo session. Second, we focused on the second-order interaction: session by attention by stimulus. None of the voxels showed significant activity for the 3-way interaction. Therefore, we conducted an $F$-map of the second-order interaction: stimulus by attention. It indicated that different brain areas were involved in stimulus processing as a function of attentional focus. Participant's parameter estimates from each significant cluster peak were entered into Statistica Program using Newman-Keuls post hoc analysis to explore further the stimulus $\times$ attention interaction.

Because effects caused by the presentation of alcohol versus soft drink versus neutral object during the bars attended condition may be very small, the RFX analyses may have been too restrictive (type II error). Therefore in addition, we applied 2 less strict generalized linear model fixed effects contrasts to test brain areas specifically involved in the automatic processing of alcohol-related stimuli. We first contrasted cerebral areas activated by alcoholic drink compared to soft-drink stimuli in the bars attended condition. Indeed, the instructions, centered on the bar orientation, were the same in the 2 conditions and the only difference between the conditions was the type of stimulus presented in the center of the screen (alcohol-related or alcohol-unrelated). No significant differences in BOLD activity between alcohol- and soft-drinkrelated pictures were observed in the bars attended condition. We then identified brain regions involved in the automatic processing of alcohol-related stimuli by contrasting brain activations following the presentation of alcoholic drinks and of neutral objects in the bars attended condition. For each cluster peak of this contrast, further Newman-Keuls post hoc analyses were conducted to test for interactions with alcohol consumption. Moreover, differences between alcoholic drinks and soft-drink presentations that were not revealed by the first contrast, which is statistically stricter, were investigated with Newman-Keuls post hoc comparisons. Finally, we tested differences in brain activations between the explicit and automatic processing of alcohol cues by contrasting brain activations following the presentation of alcoholic drinks in the attended and unattended (bars attended) conditions.

All $F$-maps were thresholded at a significance level of $p<0.001$ and then subjected to a correction for multiple testing procedures that determine critical cluster size cutoff values at a corrected significance level of 0.05 via Monte Carlo simulation (Forman et al., 1995).

\section{RESULTS}

\section{Behavioral Data}

No differences in craving measures were observed between the alcohol and placebo sessions as assessed with the visual 
analog scale $\left(T_{11}=0.66, p=0.51\right)$ and the different factors of the AAAQ (mild approach: $T_{11}=0.66, p=0.51$; intense approach: $T_{11}=-0.84, p=0.40$; avoid drinking: $T_{11}=$ $-0.25, p=0.80)$.

RTs (Table 1b) and responses were analyzed with repeated-measures ANOVAs. For RTs in the attended condition, a significant main effect of stimulus type was observed, $F(2,12)=9.75, p=0.003$. A Newman-Keuls post hoc test showed that participants were slower to judge whether they wanted to drink an alcohol $(p=0.008)$ or a soft drink $(p=0.003)$ than to indicate whether the presented object was red or not. For RTs in the bars attended condition, a main effect of stimulus type was observed, $F(2,12)=12.27, p=0.001$. A Newman-Keuls post hoc test indicated that participants were faster to indicate whether the bars were of similar orientation when the central stimulus was an alcohol-related cue relative to a sof-drink-related cue $(p=0.004)$ or a neutral object ( $p=0.001$; see Fig. 2$)$. For the accuracy of the responses in the bars attended condition, no main effect of the stimulus type, $F(2,12)=1.58, p=0.24$, session, $F(1,6)=0.09, p=0.77$, or interaction, $F(2$, $12)=0.08, p=0.92$, was observed. Finally, a repeated-measures ANOVA was computed on the percentages of positive answers to the question "do you want to drink?" This ANOVA revealed no significant main effect of the stimulus type (alcohol vs. soft drink) $F(2,6)=2.83, p=0.14$, and no main effect of the session, $F(1,6)=0.10, p=0.75$. Furthermore, there was no significant interaction between the stimulus type and the session, $F(1,6)=3.55, p=0.108$.

\section{Whole-Brain Analysis}

Effect of Alcohol Administration. The ANOVA computed on the fMRI data identified brain areas with a

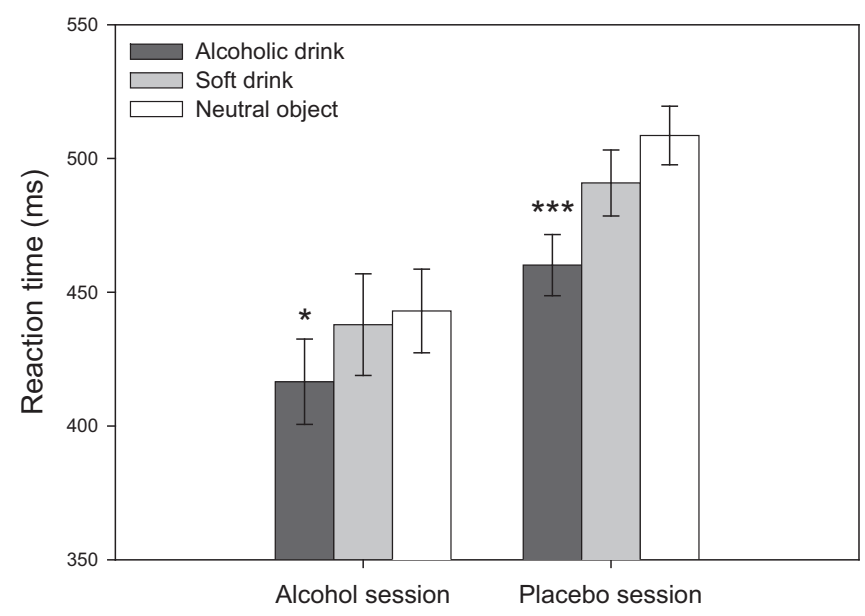

Fig. 2. Mean reaction times ( \pm SEM) for alcohol, soft drink, and neutral objects in the bars attended condition after the administration of an alcoholic or a placebo drink. Participants were faster to indicate whether the bars were of similar orientation when an alcohol-related cue was presented centrally than when a sof drink or a neutral object was presented. *Significantly different from the neutral object presentation in the bars attended condition with at least $p<0.05$; ***significantly different from the neutral object presentation in the bars attended condition with at least $p<0.001$. main effect of session. The results indicated that alcohol administration increased the activity in the right lingual gyrus, the right cingulate cortex, the left insula, the left inferior parietal lobe, and the left precentral gyrus (Table 2a).

Two-Way Interaction: Stimulus $\times$ Attention. Factorial ANOVA computed on the fMRI data identified brain areas with an RFX interaction effect between attention focus and stimulus type (Table $2 \mathrm{~b}$ ). The resulting $F$-map revealed a network of significantly active brain regions: the left putamen, the left medial orbitofrontal cortex (mOFC), the left dorsolateral prefrontal cortex (dlPFC), and the left middle temporal gyrus. Further Newman-Keuls post hoc analyses of betaweight revealed a significant higher BOLD activity in the left putamen and left middle temporal gyrus during alcoholic drinks presentation compared with neutral objects in the bars attended condition (Fig. 3). In the attended condition, differences in BOLD activity between neutral objects and drink stimuli were observed in the left OFC and the left dIPFC (Fig. 3). A difference between alcohol-related and soft-drink-related cue was also observed in the left mOFC in the condition.

Contrast: Alcohol > Neutral Stimuli in Bars Attended Condition. The contrast alcoholic drink versus neutral object in the bars attended condition revealed significant activations in extensive brain regions including the cingulate cortex, parietal regions, the left temporal gyrus, the left lingual gyrus, and the left VTA (Table 3b). However, there was no significant differential activity of the amygdala. The 3-way ANOVA computed on standardized beta values showed a significant main effect of alcohol administration in the left inferior parietal lobe. Additionally, a significant interaction between session and stimulus type indicated modulation of the activity in the left middle temporal gyrus, the left angular

Table 2. Results of Whole-Brain RFX ANOVA $(p=0.001)$ : Main Effect of the Session and Interaction of Stimulus Type $\times$ Attention Focus Effect

\begin{tabular}{|c|c|c|c|c|c|}
\hline $\begin{array}{l}\text { Functional region } \\
\text { of interest }\end{array}$ & L/R & $\begin{array}{l}\text { Talairach } \\
\text { coordinates }\end{array}$ & $\begin{array}{c}\text { Voxels } \\
\text { nbr }\end{array}$ & BA & $F$-score \\
\hline \multicolumn{6}{|c|}{ a. Main effect of session } \\
\hline \multicolumn{6}{|c|}{ Higher activation in the alcohol condition } \\
\hline Lingual gyrus & $\mathrm{R}$ & $16,-92,-1$ & 256 & 17 & 28.94 \\
\hline $\begin{array}{l}\text { Anterior cingulate } \\
\text { cortex }\end{array}$ & $\mathrm{R}$ & $3,13,31$ & 138 & 24 & 21.96 \\
\hline Insula & L & $-40,6,9$ & 595 & 13 & 27.97 \\
\hline $\begin{array}{l}\text { Inferior parietal } \\
\text { lobe }\end{array}$ & L & $-53,-41,36$ & 135 & 40 & 27.42 \\
\hline Precentral gyrus & L & $-56,-1,23$ & 54 & 6 & 22.57 \\
\hline \multicolumn{6}{|c|}{$\begin{array}{l}\text { Higher activation in the placebo condition } \\
\text { None }\end{array}$} \\
\hline \multicolumn{6}{|c|}{ b. Interaction of stimulus type and attention focus } \\
\hline Putamen & $\mathrm{L}$ & $-23,2,4$ & 62 & & 10.92 \\
\hline Orbitofrontal cortex & L & $-23,35,-6$ & 295 & 47 & 11.17 \\
\hline $\begin{array}{l}\text { Dorsolateral prefrontal } \\
\text { cortex }\end{array}$ & L & $-35,56,14$ & 61 & 10 & 10.99 \\
\hline Middle temporal gyrus & L & $-50,-47,-3$ & 68 & 37 & 10.70 \\
\hline
\end{tabular}

BA, Brodmann area; nbr, number; RFX, random-effects. 

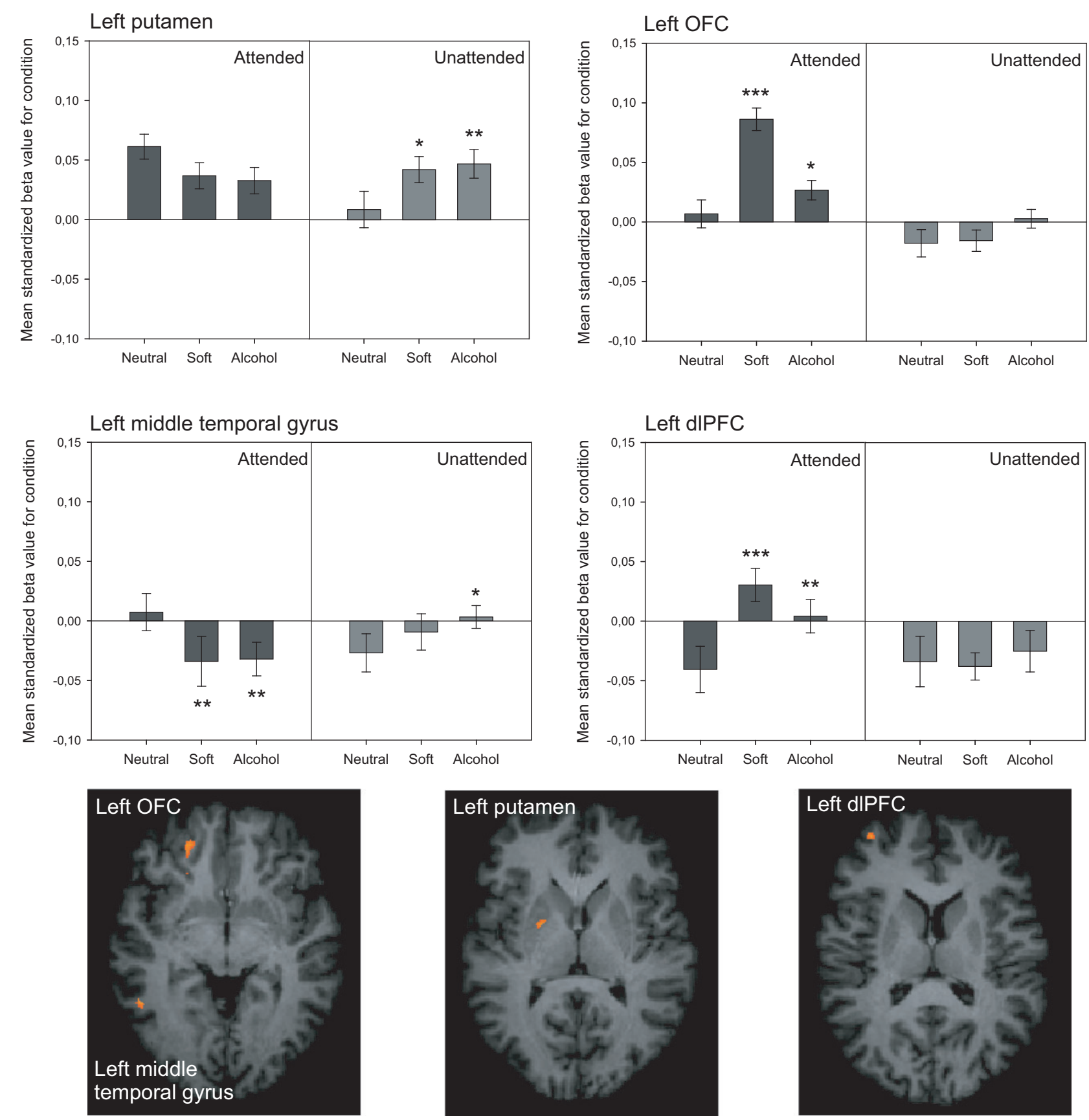

Fig. 3. Bar-plots $( \pm$ SEM) of brain regions showing significant random-effects analysis of variance $F$-test $(p<0.001)$ on stimulus type (alcoholic drink, soft drink, or neutral object) $\times$ attentional focus (object/drink attended or bars attended). *Significantly different relative to the neutral object condition with at least $p<0.05$; **significantly different relative to the neutral object condition with at least $p<0.01 ; * * *$ significantly different relative to the neutral object condition with at least $p<0.001$.

gyrus, and the left posterior cingulate cortex. Alcohol administration increased the activation in these regions during the soft-drink-related cue condition compared with the neutral object condition (Fig. 4). Contrary to our hypothesis, the administration of a priming dose of alcohol had no effect on cerebral areas involved in the automatic processing of alcohol-related cues. The same 3-way ANOVA computed on standardized beta values also revealed a significant increase in BOLD activity in the left VTA during alcoholic drinks presentation relative to soft-drink presentation in the bars attended condition (Fig. 5).

Contrast: Alcohol Stimuli in Drink Attended Condition > in Bars Attended Condition. The results indicated that the explicit evaluation of alcohol stimuli significantly activated the bilateral precuneus and a wide part of the frontal region including the medial prefrontal cortex (mPFC) and the left OFC (Table 3c). 
Table 3. Results of Linear Contrasts in RFX ANOVA ( $p=0.001)$ : (a) Alcoholic Stimuli Minus Soft-Drink Stimuli Presentation in Bars Attended Condition; (b) Alcoholic Stimuli Minus Neutral Object Stimuli Presentation in Bars Attended Condition; (c) Alcoholic Stimuli in Drink Attended Condition Minus Alcoholic Stimuli Presentation in Bars Attended Condition

\begin{tabular}{|c|c|c|c|c|c|}
\hline $\begin{array}{l}\text { Functional region } \\
\text { of interest }\end{array}$ & L/R & $\begin{array}{l}\text { Talairach } \\
\text { coordinates }\end{array}$ & $\begin{array}{l}\text { Voxels } \\
\text { nbr }\end{array}$ & $\mathrm{BA}$ & $t$-Score \\
\hline \multicolumn{6}{|c|}{$\begin{array}{l}\text { a. Alcohol minus soft in unattended conditions } \\
\text { None } \\
\text { b. Alcohol minus neutral in unattended condition }\end{array}$} \\
\hline $\begin{array}{l}\text { Anterior cingulate } \\
\text { cortex }\end{array}$ & $\mathrm{B}$ & $-2,44,0$ & 96 & 32 & 4.01 \\
\hline Cingulate cortex & B & $-2,-48,26$ & 563 & 31 & 4.26 \\
\hline $\begin{array}{l}\text { Posterior cingulate } \\
\text { cortex }\end{array}$ & $\mathrm{L}$ & $-6,-47,9$ & 174 & 29 & 4.11 \\
\hline Precuneus & B & $-2,-61,25$ & 393 & 31 & 4.02 \\
\hline Inferior parietal lobe & $\mathrm{L}$ & $-60,-40,29$ & 106 & 40 & 3.98 \\
\hline Angular gyrus & $\mathrm{L}$ & $-43,-69,35$ & 216 & 39 & 4.10 \\
\hline Supramarginal gyrus & $\mathrm{R}$ & $56,-52,25$ & 221 & 40 & 4.01 \\
\hline Middle temporal gyrus & $\mathrm{L}$ & $-60,-31,-5$ & 157 & 21 & 3.99 \\
\hline Temporal subgyral & L & $-45,-43,3$ & 51 & 37 & 4.09 \\
\hline Lingual gyrus & L & $-7,-77,-12$ & 149 & 18 & 4.11 \\
\hline $\begin{array}{l}\text { Ventral tegmental } \\
\text { area }\end{array}$ & L & $-11,-16,-17$ & 62 & & 4.08 \\
\hline Laterodorsal pons & $\mathrm{L}$ & $-12,-24,-27$ & 111 & & 4.19 \\
\hline \multicolumn{6}{|c|}{$\begin{array}{l}\text { c. Alcohol in drink attended condition minus alcohol in bars attended } \\
\text { condition }\end{array}$} \\
\hline Precuneus & $\mathrm{L}$ & $-39,-64,37$ & 778 & 39 & 4.21 \\
\hline Precuneus & $\mathrm{R}$ & $37,-62,37$ & 73 & 39 & 4.02 \\
\hline Inferior frontal gyrus & $\mathrm{R}$ & $48,5,16$ & 69 & 9 & 4.05 \\
\hline Medial frontal gyrus & $\mathrm{L}$ & $-5,18,43$ & 80 & 8 & 4.31 \\
\hline Superior frontal gyrus & L & $-13,11,64$ & 201 & 6 & 4.15 \\
\hline Superior frontal gyrus & $\bar{L}$ & $-30,48,34$ & 659 & 9 & 4.15 \\
\hline Orbitofrontal cortex & L & $-23,26,-6$ & 52 & 47 & 4.00 \\
\hline
\end{tabular}

BA, Brodmann area; nbr, number; RFX, random-effects.

\section{DISCUSSION}

This study investigated brain mechanisms involved in the automatic processing of alcohol-related cues in young heavy drinkers and its modulation by alcohol administration. In the object/drink attended condition, the explicit judgment of drink cues (i.e., alcohol and soft drink altogether) increased the activation in a wide part of the frontal region compared with the judgment of neutral cues or the presentation of unattended alcohol-related stimuli. In the bars attended (drink unattended) condition, the left putamen and the left middle
Left VTA
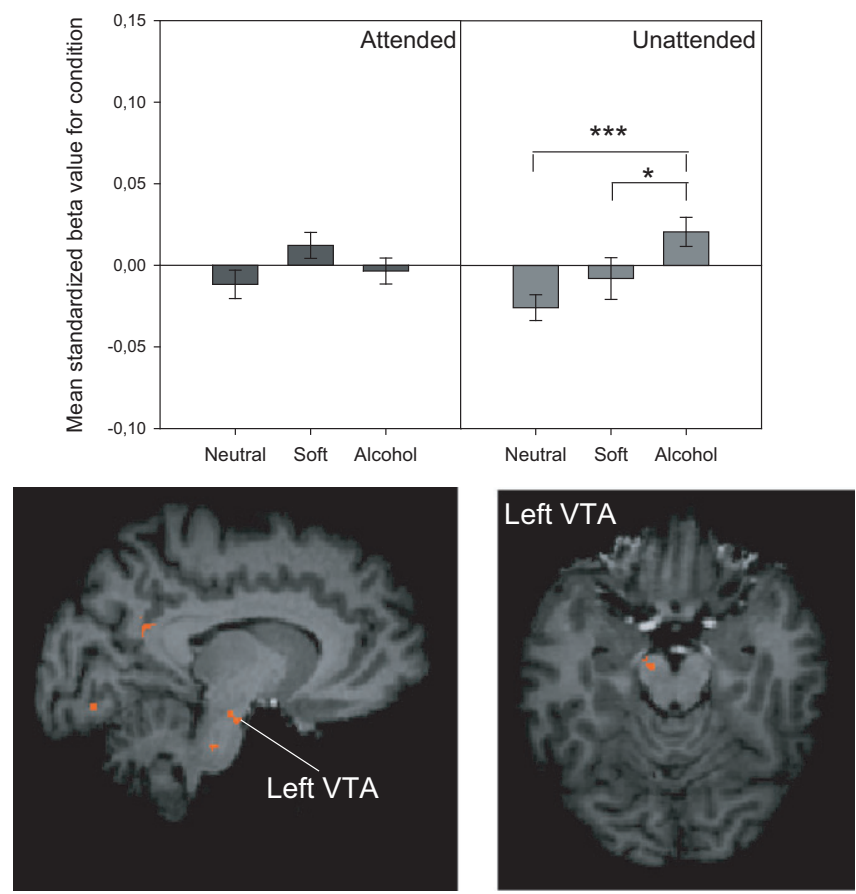

Fig. 5. Contrast plots ( \pm SEM) of the left ventral tegmental area showing significant increased in blood oxygen-level dependent activity during bars attended condition when an alcohol-related drink was presented compared to soft drink, as shown by Newman-Keuls post hoc analyses of beta-weight. *Significantly different with at least $p<0.05$; ***significantly different with at least $p<0.001$.

temporal gyrus were more activated by the presentation of task-irrelevant drink cues compared with neutral cues. Moreover, when contrasted to neutral cues, task-irrelevant alcoholrelated cues elicited activity in a large network of cerebral areas including visual and temporal regions, the bilateral $\mathrm{ACC}$, and the posterior cingulate cortex. In addition, the VTA was particularly activated by task-irrelevant alcoholrelated cues compared to task-irrelevant soft-drink-related cues. Finally, alcohol administration increased the activation in the left middle temporal gyrus, the left angular gyrus, and the left posterior cingulate cortex when soft-drink-related cues were presented.
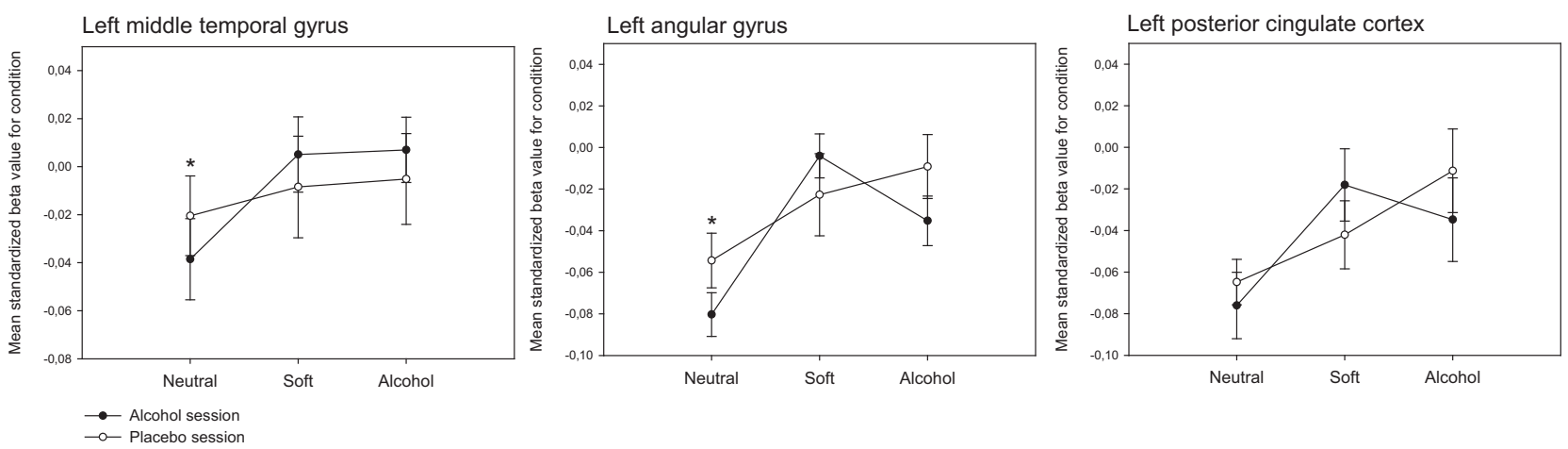

Fig. 4. Contrast plots ( \pm SEM) of brain regions activated in the bars attended condition when an alcohol-related drink was presented by contrast to a neutral object, as shown by a random-effects analysis of variance $(p<0.001)$. *Significantly different between alcohol and placebo session with at least $p<0.05$. 
The major finding emerging from this sample is the activation of the left VTA in the bars attended (alcohol unattended) condition when alcohol-related stimuli were presented compared to soft drink. This area is one of the major sources of dopamine neurons within the brain and is involved in the processing of motivationally salient stimuli (Robinson and Berridge, 2003). In heavy drinkers, the activation of this dopaminergic midbrain nucleus has been previously observed following the presentation of alcohol-related cues (Filbey et al., 2008; Kareken et al., 2004). In line with those studies, our results indicate that the VTA is involved in the automatic processing of alcohol-related cues in young heavy drinkers. Interestingly, a recent study also reported activations in the nucleus accumbens, one of the brain targets of dopaminergic neurons from the VTA, in alcohol-dependent patients showing an alcohol-approach bias (Wiers et al., 2014).

Except for the VTA, we did not find specific neural responses for alcohol-related cues relative to soft-drinkrelated cues. Overall, similar patterns of activation were observed during their automatic processing. One explanation could be that young heavy drinkers would exhibit strong appetitive reaction toward these 2 reward stimuli. In this population, nonalcoholic drinks could be associated with alcoholic drinks as youngsters often drink alcohol mixed with soft drinks. Supporting this explanation, Wiers and colleagues (2009) found a large approach bias both for alcoholic drinks and for soft-drink stimuli in heavy drinkers carrying the OPRM1 G-allele. However, our behavioral results showed that alcohol-related and soft-drink-related cues were processed differently in the unattended condition. Indeed, participants judged the peripheral stimulus orientation quicker when an alcohol-related cue was presented relative to a soft-drink-related cue. Faster responses to alcohol cues compared to neutral cues have already been reported in occasional drinkers, problematic drinkers, and alcohol-dependent patients using various attentional and inhibition tasks (Kreusch et al., 2013; Tapert et al., 2004). Alcohol-related cues induce an increased reactivity as indicated by physiological measures (Herrmann et al., 2001) and behavioral responses to rewards (Kambouropoulos and Staiger, 2001). The whole-brain analysis used in this study was statistically very strict and did probably not allow to highlight the neural correlates of this increased reactivity for alcohol-related cues compared to soft-drink-related cues. Other studies are necessary to further investigate that question. Indeed, previous studies which compared neural modulation by task-irrelevant alcohol-related cues in nondependent subjects used neutral cues as control condition (Nikolaou et al., 2013).

In the present study, large activations of interconnected brain structures were observed during the irrelevant presentation of alcohol-related cues compared to neutral cues. An involvement of these regions has previously been shown during craving and attentional bias for alcohol. They include the anterior and posterior cingulate gyrus (Myrick et al., 2004; Vollstädt-Klein et al., 2012), the left putamen (Braus et al., 2001; Vollstädt-Klein et al., 2012), the left temporal gyrus
(Tapert et al., 2004), and the left inferior parietal lobule (Fryer et al., 2013). We also found activations of visual processing areas, such as the precuneus and the lingual gyrus, suggesting a deep visual automatic processing of alcoholrelated cues in comparison with neutral object cues (Braus et al., 2001). We did not find any significant implication of the amygdala in the bars attended conditions, suggesting that this area is not clearly involved in the automatic processing of alcohol-related stimuli (Pessoa et al., 2002; Siep et al., 2009). Nevertheless, its activation was also not observed in the attended condition, unlike the frontal region, including the left mOFC, the mPFC, and the dIPFC that are typically involved in conscious and explicit processing of rewarding stimuli (Goldstein and Volkow, 2002; Siep et al., 2009; Wilson et al., 2004).

The last aim of the present study was to test whether alcohol administration modulates the activity during the automatic processing of alcohol-related cues. Consistent with previous studies, alcohol administration increased activations in the insula and precentral regions, as well as in the anterior cingulate regions (Calhoun et al., 2004; Gilman et al., 2008). Unexpectedly, no specific alterations of the cerebral response to alcohol-related cues were observed after the administration of a low dose of alcohol. Increased activations in the left middle temporal gyrus, the left angular gyrus, and the left posterior cingulate cortex were only observed when soft-drink-related cues were presented. In contrast, Nikolaou and colleagues (2013) found that the administration of a low dose of alcohol $(0.4 \mathrm{~g} / \mathrm{kg})$ disturbed cerebral responses to a visual display consisting of alcoholic drinks in hypothalamic regions compared to a neutral background. Two methodological aspects might explain the differences between this study and the current one. First, Nikolaou and colleagues (2013) used different participants in the alcohol and in the placebo sessions, whereas we used a more robust within-subject design. Second, they only used neutral cues as control condition, while soft-drink-related and neutral cues were included in our analyses.

Although the present study generated interesting results, some limitations should be acknowledged. First, only hazardously drinking male students were included, which limits the generalizability of the results. Indeed, previous studies showed that female heavy drinkers responded differently to alcohol cues compared with males (Kreusch et al., 2013). Future studies will be required to test whether the present results may be generalized to other populations, such as alcohol-dependent patients or female heavy drinkers. Although light drinkers typically do not show an attentional bias for alcohol, it would be interesting to carry out a similar study in light drinkers. Indeed, because of the particular nature of alcohol cues, we cannot totally rule out that the unattended presentation of such cues in light drinkers would produce a different pattern of brain activations relative to soft-drinkrelated cues even in the absence of an attentional bias. Additionally, due to the central presentation of the images in our task, we cannot guarantee that stimuli were totally task 
irrelevant in the so-called condition (i.e., when participants had to process peripheral bars). Future studies should confirm our results with other types of displays or tasks. Finally, we present preliminary data on a limited number of subjects, such that subtle differences in brain activations might have been missed.

In conclusion, our findings suggest that a similar pattern of activation when heavy drinkers process alcohol-related or soft-drink-related cues in an automatic fashion, with the exception of the VTA which was particularly activated by the processing of task-irrelevant alcohol-related cues. Finally, low dose of alcohol did not modulate the neural substrates involved in the processing of salient alcohol-related cues. This study is the first to examine the brain correlates of relatively automatic processing of alcohol-related cues relative to soft-drink-related cues in young heavy drinkers.

\section{REFERENCES}

Adams S, Ataya AF, Attwood AS, Munafò MR (2012) Effects of acute alcohol consumption on alcohol-related cognitive biases in light and heavy drinkers are task-dependent. J Psychopharmacol 26:245-253.

Babor TF, Higgins-Biddle JC, Saunders JB, Monteiro MG (2001) AUDIT: The Alcohol Use Disorders Identification Test, Guidelines for Use in Primary Care. 2nd ed. World Health Organization, Geneva.

Bragulat V, Dzemidzic M, Talavage T, Davidson D, O'Connor SJ, Kareken DA (2008) Alcohol sensitizes cerebral responses to the odors of alcoholic drinks: an fMRI study. Alcohol Clin Exp Res 32:1124-1134.

Braus DF, Wrase J, Grüsser S, Hermann D, Ruf M, Flor H, Mann K, Heinz A (2001) Alcohol-associated stimuli activate the ventral striatum in abstinent alcoholics. J Neural Transm 108:887-894.

Calhoun VD, Pekar JJ, Pearlson GD (2004) Alcohol intoxication effects on simulated driving: exploring alcohol-dose effects on brain activation using functional MRI. Neuropsychopharmacology 29:2097-2117.

Carlsson K, Petersoon KM, Lundqvist D, Karlsson A, Ingvar M, Ohman A (2004) Fear and the amygdala: manipulation of awareness generates differential cerebral responses to phobic and fear-relevant (but nonfeared) stimuli. Emotion 4:340-353.

Cox WM, Brown MA, Rowlands LJ (2003) The effects of alcohol cue exposure on non-dependent drinkers' attentional bias for alcohol-related stimuli. Alcohol Alcohol 38:45-49.

Cox WM, Yeates GN, Regan CM (1999) Effects of alcohol cues on cognitive processing in heavy and light drinkers. Drug Alcohol Depend 55:85-89.

Dager AD, Anderson BM, Stevens MC, Pulido C, Rosen R, Jiantonio-Kelly RE, Sisante JF, Raskin SA, Tennen H, Austad CS, Wood RM, Fallahi CR, Pearlson GD (2013) Influence of alcohol use and family history of alcoholism on neural response to alcohol cues in college drinkers. Alcohol Clin Exp Res 37:161-171.

Derogatis LR (1994) Symptom Checklist-90-R: Administrative Scoring and Procedures Manual. NCS Pearson, Minneapolis, MN.

Duka T, Townshend JM (2004) The priming effect of alcohol pre-load on attentional bias to alcohol-related stimuli. Psychopharmacology 176: $353-361$.

Fernie G, Christiansen P, Cole JC, Rose AK, Field M (2012) Effects of $0.4 \mathrm{~g} / \mathrm{kg}$ alcohol on attentional bias and alcohol-seeking behaviour in heavy and moderate social drinkers. J Psychopharmacol 26:1017-1025.

Field M, Cox WM (2008) Attentional bias in addictive behaviors: a review of its development, causes, and consequences. Drug Alcohol Depend 97: $1-20$.

Field M, Wiers RW, Christiansen P, Fillmore MT, Verster JC (2010) Acute alcohol effects on executive function and implicit cognition: implications for loss of control. Alcohol Clin Exp Res 34:1346-1352.
Filbey FM, Claus E, Audette AR, Niculescu M, Banich MT, Tanabe J, Du YP, Hutchison KE (2008) Exposure to the taste of alcohol elicits activation of the mesocorticolimbic neurocircuitry. Neuropsychopharmacology 33:1391-1401.

Forman SD, Cohen JD, Fitzgerald M, Eddy WF, Mintun MA, Noll DC (1995) Improved assessment of significant activation in functional magnetic resonance imaging (fMRI): use of a cluster-size threshold. Mag Reson Med 33:636-647.

Franken IH (2003) Drug craving and addiction: integrating psychological and neuropsychopharmacological approaches. Prog Neuropsychopharmacol Biol Psychiatry 27:563-579.

Fryer SL, Jorgensen KW, Yetter EJ, Daurignac EC, Watson TD, Shanbhag H, Krystal JH, Mathalon DH (2013) Differential brain response to alcohol cue distractors across stages of alcohol dependence. Biol Psychol 92:282-291.

Garland EL, Franken IHA, Howard MO (2012) Cue-elicited heart rate variability and attentional bias predict alcohol relapse following treatment. Psychopharmacology 222:17-26.

Gilman JM, Ramchandani VA, Davis MB, Bjork JM, Hommer DW (2008) Why we like to drink: a functional magnetic resonance imaging study of the rewarding and anxiolytic effects of alcohol. J Neurosci 28:4583-4591.

Goldstein RZ, Volkow ND (2002) Drug addiction and its underlying neurobiological basis: neuroimaging evidence for the involvement of the frontal cortex. Am J Psychiatry 159:1642-1652.

Heinz A, Beck A, Grusser SM, Grace AA, Wrase J (2009) Identifying the neural circuitry of alcohol craving and relapse vulnerability. Addict Biol 14:108-118.

Herrmann MJ, Weijers HG, Wiesbeck GA, Böning J, Fallgatter AJ (2001) Alcohol cue-reactivity in heavy and light social drinkers as revealed by event-related potentials. Alcohol Alcohol 36:588-593.

Ihssen N, Cox WM, Wiggett A, Fadardi JS, Linden DE (2011) Differentiating heavy from light drinkers by neural responses to visual alcohol cues and other motivational stimuli. Cereb Cortex 21:1408-1415.

Johnsen BH, Laberg JC, Cox WM, Vaksdal A, Hugdahl K (1994) Alcoholic subjects' attentional bias in the processing of alcohol-related words. Psychol Addict Behav 8:111-115.

Kambouropoulos N, Staiger PK (2001) The influence of sensitivity to reward on reactivity to alcohol-related cues. Addiction 96:1175-1185.

Kareken DA, Claus ED, Sabri M, Dzemidzic M, Kosobud AE, Radnovich AJ, Hector D, Ramchandani VA, O'Connor SJ, Lowe M, Li T (2004) Alcohol-related olfactory cues activate the nucleus accumbens and ventral tegmental area in high-risk drinkers: preliminary findings. Alcohol Clin Exp Res 28:550-557.

Kreusch F, Vilenne V, Quertemont E (2013) Response inhibition toward alcohol-related cues using an alcohol go/no-go task in problem and nonproblem drinkers. Addict Behav 38:2520-2528.

Marlatt GA, Rohsenow DJ (1980) Cognitive processes in alcohol use: expectancy and the balanced placebo design, in Advances in Substance Abuse: Behavioral and Biological Research (Mello NK ed), pp 159-199. JAI Press, Greenwich, CT.

McEvoy PM, Stritzke WG, French DJ, Lang AR, Ketterman RL (2004) Comparison of three models of alcohol craving in young adults: a crossvalidation. Addiction 99:482-497.

Myrick H, Anton RF, Li X, Henderson S, Drobes D, Voronin K, George MS (2004) Differential brain activity in alcoholics and social drinkers to alcohol cues: relationship to craving. Neuropsychopharmacology 29:393-402.

Nikolaou K, Field M, Critchley H, Duka T (2013) Acute alcohol effects on attentional bias are mediated by subcortical areas associated with arousal and salience attribution. Neuropsychopharmacology 38:1365-1373.

Noël X, Colmant M, Van Der Linden M, Bechara A, Bullens Q, Hanak C, Verbanck P (2006) Time course of attention for alcohol cues in abstinent alcoholic patients: the role of initial orienting. Alcohol Clin Exp Res 30: 1871-1877.

Pessoa L, McKenna M, Gutierrez E, Ungerleider LG (2002) Neural processing of emotional faces requires attention. Proc Natl Acad Sci USA 99:11458-11463. 
Pessoa L, Padmala S, Morland T (2005) Fate of unattended fearful faces in the amygdala is determined by both attentional resources and cognitive modulation. NeuroImage 28:249-255.

Robinson TE, Berridge KC (2003) Addiction. Annu Rev Psychol 54:25-53.

Saunders JB, Aasland OG, Babor TF, de la Fuente JR, Grant M (1993) Development of the alcohol use disorders identification test (AUDIT): Word Health Organization collaborative project on early detection of persons with harmful alcohol consumption: II. Addiction 88:791-804.

Schacht JP, Anton RF, Myrick H (2013) Functional neuroimaging studies of alcohol cue reactivity: a quantitative meta-analysis and systematic review. Addict Biol 18:121-133.

Schoenmakers T, Wiers RW, Field M (2008) Effects of a low dose of alcohol on cognitive biases and craving in heavy drinkers. Psychopharmacology 197:169-178.

Siep N, Roefs A, Roebroeck A, Havermans R, Bonte ML, Jansen A (2009) Hunger is the best spice: an fMRI study of the effects of attention, hunger and calorie content on food reward processing in the amygdala and orbitofrontal cortex. Behav Brain Res 198:149-158.

Stacy A, Wiers RW (2010) Implicit cognition and addiction: a tool for explaining paradoxical behavior. Annu Rev Clin Psychol 6:551575.

Tapert SF, Brown GG, Baratta MV, Brown SA (2004) fMRI BOLD response to alcohol stimuli in alcohol dependent young women. Addict Behav 29:33-50.

Townshend JM, Duka T (2001) Attentional bias associated with alcohol cues: differences between heavy and occasional drinkers. Psychopharmacology 157:67-74.

Van Dillen LF, Heslenfel DJ, Koole SL (2009) Tuning down the emotional brain: an fMRI study of the effects of cognitive load on the processing of affective images. NeuroImage 45:1212-1219.
Vollstädt-Klein S, Loeber S, Richter A, Kirsch M, Bach P, von der Goltz C, Hermann D, Mann K, Kiefer F (2012) Validating incentive salience with functional magnetic resonance imaging: association between mesolimbic cue reactivity and attentional bias in alcohol-dependent patients. Addict Biol 17:807-816.

Vuilleumier P, Armony JL, Driver J, Dolan RJ (2001) Effects of attention and emotion on face processing in the human brain: an event related fMRI study. Neuron 30:829-841.

Wiers RW, Bartholow BD, van den Wildenberg E, Thush C, Engels RC, Sher KJ, Grenard J, Ames S, Stacy AW (2007) Automatic and controlled processes and the development of addictive behaviors in adolescents: a review and a model. Pharmacol Biochem Behav 86:263-283.

Wiers RW, Hoogeveen KJ, Sergeant JA, Gunning WB (1997) High and low dose expectancies and the differential associations with drinking in male and female adolescents and young adults. Addiction 92:871-888.

Wiers RW, Rinck M, Dictus M, van den Wildenberg E (2009) Relatively strong automatic appetitive action-tendencies in male carriers of the OPRM1 G-allele. Genes Brain Behav 8:101-106.

Wiers CE, Stelzel C, Park SQ, Gawron CK, Ludw VU, Gutwinski S, Heinz A, Lindenmeyer J, Wiers RW, Walter H, Bermpohl F (2014) Neural correlates of alcohol-approach bias in alcohol addiction: the spirit is willing but the flesh is weak for spirits. Neuropsychopharmacology 39:688-697.

Wilson SJ, Sayette MA, Fiez JA (2004) Prefrontal responses to drug cues: a neurocognitive analysis. Nat Neurosci 7:211-214.

De Wit H, Chutuape MA (1993) Increased ethanol choice in social drinkers following ethanol preload. Behav Pharmacol 4:29-36.

Wrase J, Grüsser SM, Klein S, Diener C, Hermann D, Flor H, Mann K, Braus DF, Heinz A (2002) Development of alcohol-associated cues and cue-induced brain activation in alcoholics. Eur Psychiatry 17:287-291. 